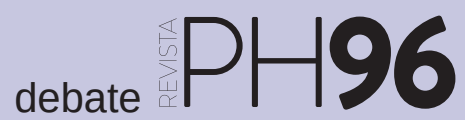

a debate Memoria democrática en la construcción de la historia y el patrimonio

| coordina Josefina Cuesta Bustillo

\title{
La memoria brota de la experiencia, y viceversa
}

Carlos García de las Bayonas Abelleira | estudiante del Máster Universitario en Patrimonio Cultural en el Siglo XXI: Gestión en Investigación, Universidad Complutense de Madrid

URL de la contribución <www.iaph.es/revistaph/index.php/revistaph/article/view/4312>

Desde la aprobación de la Ley 57/2007 de Memoria Histórica de España, el binomio "memoria histórica" ha tenido un difícil encaje en el panorama político español. Ciertamente, el vocablo, ora controvertido, ora polémico, puede dar para un debate en sí mismo, más allá del ámbito de la propia ley. Habrá quien lo considere redundante -un pleonasmo, vaya- en cuanto a que toda historia es un ejercicio de memoria desde la contemporaneidad y la subjetividad; una proyección del presente hacia el pasado con miras hacia el futuro. Habrá quien lo considere desleal a la expresión hermana de "memoria democrática" en cuanto a que, en términos históricos, ningún presente ha sido tan democrático como el nuestro. Habrá, incluso, quien lo considere un secuestro, en cuanto a que no da cabida a la pluralidad y a la colectividad.

En realidad, el término (de forma genérica) no es más que una convención social empleada para encerrar un concepto. En este caso, se trata de una acuerdo -fundamentalmente político- para referirse al esfuerzo grupal realizado en pos de la recuperación de la memoria republicana, de las víctimas de la Guerra Civil y la posterior dictadura franquista. Sea como fuere, el término debería reflejar la pluralidad, la mirada abierta, que se intuye en la idea. Por lo tanto, sería más positivo para el debate hablar de memorias (múltiples, cruzadas, compartidas), que no de una sola memoria (estanca, objetivizante, institucionalizada).

Más allá de devaneos dialécticos, considero de mayor provecho poner la atención en el proceso subyacente. Se hable de memoria (histórica, democrática, colectiva, crítica, pública, nacional, oficial, etc.) o memorias (inserte aquí el epíteto que prefiera), es necesario destacar que la cuestión mnemónica no deja de ser una activación simbólica. Quienes provengan del campo del patrimonio cultural o de la antropología conocen los riesgos que entrañan los procesos de activación patrimonial no consensuados, la patrimonialización sesgada o las apropiaciones con fines políticos, que "no pueden ni oscurecer ni, menos, sustituir o cambiar la Historia" (ARÓSTEGUI, 2009: 60). Experiencias internacionales como las de Alemania, Italia, Argentina o, más recientemente, Perú, entre otras, pueden ser edificantes en este sentido.

En España, en la actualidad, parecemos haber llegado a un impasse, después de un avance moderado y una sobrecarga de retrasos. Hasta ahora, las pocas acciones efectivas que se han llevado a cabo han estado dirigidas, fundamentalmente, desde las administraciones y únicamente porque la presión del asociacionismo ha encontrado algún resquicio entre tanto tapón institucional (VELASCO MESA, 2017). La discusión no se debería quedar en el plano de las instituciones porque la problemática de la desmemoria o de la patrimonialización de la "memoria oscura" (HERNÀNDEZ I MARTí, 2010) realmente atañe a toda la ciudadanía ya que implica una selección consensuada de recuerdos, experiencias, sensaciones y percepciones.

El debate, por lo tanto, debe ser multifocal. Desde el mundo académico y la investigación (a través de una historia comprometida), desde las asociaciones civiles, las plataformas ciudadanas, los medios de comunicación (que tanta repercusión tienen y tanto ruido producen), entre muchos otros, se debe favorecer el encuentro honesto de posturas, aunque algunas nos disgusten, aunque ciertas nos contradigan y otras tantas nos contraríen. Todo ello, por supuesto, partiendo de los principios democráticos actuales y teniendo en mente el aprendizaje y el compromiso social. 


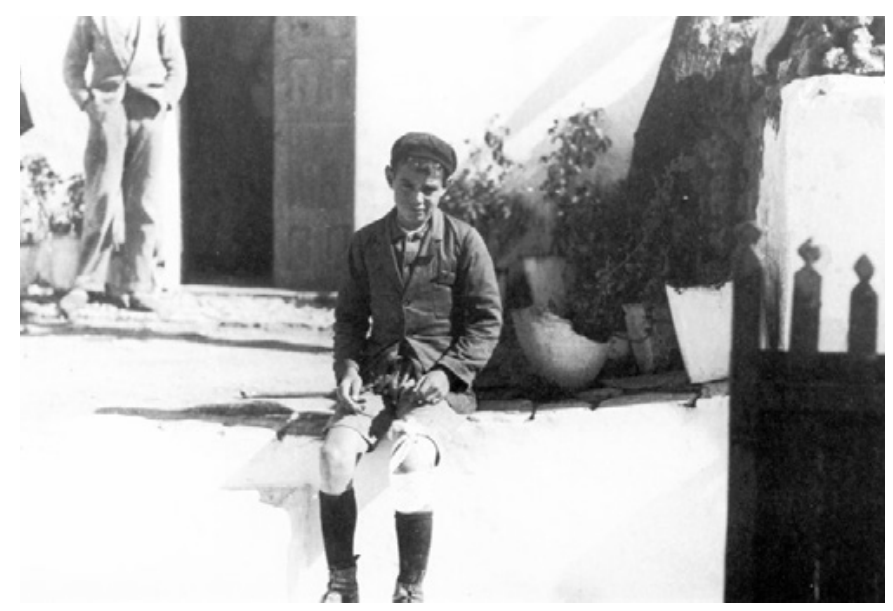

"El niño Salvador del Río (Benalup-Casas Viejas, 1933)" | fuente SERRANO GÓMEZ, 2000

En lo que al patrimonio respecta, me gustaría traer a colación la experiencia de Benalup-Casas Viejas como ejemplo de documentación, difusión e interpretación sin banalización. En dicha localidad gaditana abordaron la cuestión de su memoria con anterioridad a la aprobación de Ley 2/2017 de Memoria Histórica y Democrática de Andalucía. Concretamente, desde su segregación en 1991 de Medina-Sidonia (con el nombre de Benalup de Sidonia) y, más específicamente, desde que se cambiara su denominación a Benalup-Casas Viejas en 1999, la resignificación consciente de la localidad ha ido orientada a recordar los sucesos que allí acontecieron a inicios de la II República.

Tras un primer intento en 2009, en septiembre de 2018 la Dirección General de Bienes Culturales y Museos de la Junta de Andalucía incoó de nuevo el procedimiento para la inscripción en el Catálogo General del Patrimonio Histórico Andaluz como Bien de Interés Cultural (BIC), con la tipología de sitio histórico, del lugar de los sucesos de Casas Viejas. El intento de declaración estuvo acompañado por un exhaustivo ejercicio de documentación y una enorme implicación de muy diversos agentes, entre los que destacan los propios de la localidad (no hay más que consultar los trabajos del IES Casas Viejas disponibles online). Como resultado, queda una puesta en valor del patrimonio inmueble relacionado con los pro- pios sucesos, un ejercicio de memoria colectiva (a través de la oralidad, la inclusión de testimonios y la documentación gráfica) que incluyó la perspectiva de género, y un reconocimiento al valor simbólico del hecho en sí. En definitiva, retomo y cierro con la idea inicial de que el debate ha de ser plural y colectivo, aunque con matices. Para que verdaderamente sea un debate entre iguales y no una negociación, inevitablemente se ha de dignificar primeramente la memoria de los desaparecidos, de los torturados, de los represaliados. Todo ello, con el "derecho a la verdad" por delante. En lo que al patrimonio controvertido se refiere el atolladero epistemológico se vuelve harto estrecho porque nuestra responsabilidad ética con el pasado se hace una con el presente. Experiencias micro como el caso de Benalup-Casas Viejas u otros (como Belchite o el proyecto BAMSA), que brotan de la memoria y al mismo tiempo la alimentan, pueden ser claves en el camino del encuentro.

\section{BIBLIOGRAFÍA}

- ARÓstegul, J. (2009) La Ley de Memoria Histórica: reparación e insatisfacción. Patrimonio Cultural de España [en línea], n. ${ }^{\circ}$ 1, 2009, pp. 41-60 <http://ccfib.mcu.es/patrimonio/ docs/MC/IPHE/PatrimonioCulturalE/N1/08_PCE1_Ley_ Reparacion.pdf> [Consulta: 23/11/2018]

- HERNÀNDEZ I MARTí, G. M. (2010) La memoria oscura: El patrimonio cultural y su sombra. En RIVERA BLANCO, J. (coord.) VI Congreso Internacional "Restaurar la Memoria": La gestión del patrimonio: hacia un planteamiento sostenible, Vol. 2 (Comunicaciones), 2010, pp. 629-637 [en línea] <http://www. academia.edu/2201415/La_memoria_oscura._El_patrimonio_ cultural_y_su_sombra> [Consulta: 24/11/2018]

- SERRANO GÓmeZ, J. J. (2000) Los Sucesos de Casas Viejas (Cádiz, 1933). Catálogo de la Exposición fotográfica de Serrano y Sánchez del Pando. Cádiz: Fundación Provincial de Cultura de la Diputación de Cádiz, Ayuntamiento de Casas Viejas, 2000

- VELAsco MESA, C. (2017) Historia y memoria: un mismo combate. Aportaciones epistemológicas de Historia a Debate a las controversias acerca de la memoria histórica. Memorias: revista digital de historia y arqueología desde El Caribe [en línea], n. ${ }^{\circ} 33,2017$, pp. 120-141 <http://rcientificas.uninorte.edu. co/index.php/memorias/article/view/10048/214421442950> [Consulta: 24/11/2018] 